\title{
Representaciones sociales sobre la migración haitiana en la escuela chilena
}

\author{
Juana Lorena Campos-Bustos, Ph. D. ${ }^{a}$ \\ Universidad de Chile, Chile
}

vani@uchile.cl

\section{Resumen (analítico)}

Se parte de la siguiente pregunta: ¿cómo representan las y los escolares chilenos de educación básica de una escuela pública de Santiago a sus compañeras y compañeros migrantes haitianos? Se utiliza un enfoque cuantitativo que recurre a la encuesta como instrumento fundamental de estudio. Las variables examinadas son el género y el nivel escolar según la edad del estudiantado, dando como resultado, por un lado, que las estudiantes de género femenino y quienes cursan de $1^{\circ}$ a $4^{\circ}$ año básico tienden a representar socialmente al estudiantado haitiano de modo positivo y, por otro lado, que los estudiantes de género masculino y quienes cursan de $5^{\circ}$ a $8^{\circ}$ año básico tienden a generar representaciones prejuiciosas y desestimadas de las y los migrantes.

\section{Palabras clave}

Representaciones sociales, migrante, educación intercultural, infancia.

\section{Thesauro}

Tesauro de Ciencias Sociales de la Unesco.

\section{Para citar este artículo}

Campos-Bustos, J. L. (2022). Representaciones sociales sobre la migración haitiana en la escuela chilena. Revista Latinoamericana de Ciencias Sociales, Niñez y Juventud, 20(1), 1-22. https://dx.doi.org/10.11600/rlcsnj.20.1.4712

\section{Historial}

Recibido: 27.10 .2020

Aceptado: 03.06.2021

Publicado: 30.11.2021

\section{Información artículo}

Este artículo es una parte del estudio denominado Migrantes haitianos en la escuela pública chilena, que ha realizado la autora a la luz del Grupo de Estudios Interculturalidad: Encuentros y Desencuentros, entre los años 2017 y 2019 en la Facultad de Filosofía y Humanidades de la Universidad de Chile. Área: ciencias sociales. Subárea: educación. 


\section{Social representations of Haitian migration in Chilean schools}

\section{Abstract (analytical)}

This research begins with the following question: How do Chilean school children in a public primary school in Santiago represent their Haitian migrant classmates? A quantitative approach was with a survey selected as the main data collection tool. The variables included gender and year level. The results show that female students and those aged between 6 and 9 tend to socially represent Haitian students in an evaluative manner while male students and those aged between 10 and 15 tend to generate prejudiced and dismissive representations of migrants.

Keywords

Social representations, migrant, intercultural education, childhood.

\section{Representações sociais sobre a migração haitiana na escola chilena}

\section{Resumo (analítico)}

O artigo parte da seguinte pergunta: Como os escolares chilenos do ensino básico de uma escola pública de Santiago representam seus companheiros migrantes haitianos? É utilizada uma abordagem quantitativa que utiliza a pesquisa como um instrumento de estudo fundamental. As variáveis examinadas são gênero e nível escolar de acordo com a idade do corpo discente, resultando, por um lado, que estudantes do sexo feminino e entre 6 e 9 anos tendem a representar socialmente os alunos haitianos de forma avaliativa e, por outro lado, que estudantes do sexo masculino e entre 10 e 15 anos tendem a gerar representações preconceituosas e subestimadas dos migrantes.

\section{Palavras-chave}

Representações sociais, migrantes, educação intercultural, infância.

\section{Información autora}

[a] Juana Lorena Campos-Bustos. Doctora en Literatura Hispanoamericana y Chilena, Universidad de Chile. Magíster en Lengua Española, Universidad de Chile. (iD) 0000-0001-5723-8659. H5: 2. Correo electrónico: vani@uchile.cl 


\section{Introducción}

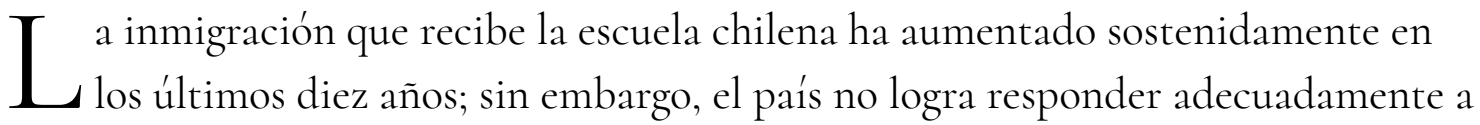
ella (Castillo et al., 2018; Stefoni et al., 2016, Superintendencia de Educación, 2016; Thayer, 2014). Una de las mayores problemáticas que surgen de esta situación es aquella referida a las representaciones sociales negativas acerca de la alteridad que se generan por parte de toda la sociedad, las cuales afectan directamente a los hijos e hijas de migrantes (Departamento de extranjería y migración, 2019; Rojas et al., 2015). Explica Tijoux (2013) que los niños y niñas migrantes cargan con la extranjeridad negada de sus madres y padres, percepción que guarda relación con la ideología racista sobre la que se construye la nación chilena; de modo que la xenofobia termina convirtiéndose en el sentido común que muchas veces rige las relaciones dentro del aula. El migrante en Latinoamérica encarna lo malo y lo peligroso (González, 2017; Mendoza \& Lazzaro-Salazar, 2019; Palacios, 2014), en especial si es de piel oscura y pobre.

En relación al migrante que llega a la escuela pública chilena, trabajos recientes (Galaz et al., 2017; Salas et al., 2017) indican que la discriminación, tanto explícita como implícita, es una realidad en las comunidades educativas chilenas aun cuando se acepta oficialmente el ingreso de estudiantes migrantes a la escuela. Se han estudiado las apreciaciones docentes (Cerón et al., 2017; Sanhueza et al., 2014) y las que emiten los escolares (Pavez et al., 2019; Unicef, 2011), evidenciándose en ambas instancias la representación del estudiante migrante como un sujeto deficitario. Se observa, además, que la interseccionalidad de vulneraciones que afecta a niños y niñas migrantes como el color de piel, la pobreza, la sexualización prematura, entre otros factores, los ubica en posición de subordinación permanente, generando una polivictimización desde todos los ámbitos sociales en que participan (Galaz et al., 2019). A nivel nacional, los estudios se multiplican en el reconocimiento de las variadas formas de vulneración de derechos, siendo hoy en día el norte del país un lugar crítico en la violencia frente a la infancia migrante (Galaz et al., 2021; Marín-Alaniz, 2018) 
El estudio de Unicef (2011), en relación a las representaciones que la población infantil y juvenil de Chile genera, mostró datos cuantitativos y comparativos entre el 2004 y 2011, en los que se destaca que una parte importante de adolescentes, niñas y, especialmente, niños creen que las personas de otros países son inferiores. Asimismo, se observa que el prejuicio y la discriminación se da mayoritariamente en las y los estudiantes de establecimientos municipales de cursos iniciales. Por último, se observó que estudiantes de género femenino son quienes presentan menos prejuicios en temas discriminatorios en distintos ámbitos. Complementariamente, la Superintendencia de Educación (2016) muestra que la migración en la escuela está marcada por la discriminación, el racismo y la xenofobia; aunque reconoce que las comunidades educativas no cuentan con metodologías, recursos didácticos ni orientaciones técnico-pedagógicas que ayuden a la inclusión real de niños y niñas migrantes, más allá de las voluntades personales de los equipos directivos y docentes.

En el contexto descrito resulta de gran interés conocer en detalle qué piensan las y los escolares chilenos respecto al alumnado migrante, en particular, sobre niñas y niños haitianos, quienes junto con su color de piel poseen una característica sobresaliente: el creole, su lengua materna. El objetivo de esta investigación es mostrar de forma descriptiva las representaciones sociales que escolares chilenos de educación básica de una escuela pública configuran respecto a sus compañeras y compañeros migrantes haitianos. Por lo anterior, la pregunta que rige el estudio es: ¿cómo representan las y los escolares chilenos de educación básica de una escuela pública de Santiago a sus compañeras y compañeros haitianos?

Para cumplir el objetivo de la investigación se plantea un estudio cuantitativo con la finalidad de acceder a datos representativos en relación a variables concretas y, en este contexto, el instrumento elegido es la encuesta de preguntas cerradas y abiertas. Si bien la realidad social es más compleja y críptica de lo que se puede observar desde una indagación cuantitativa, esta perspectiva parece un buen acercamiento inicial, dada su objetividad, representatividad y replicabilidad, a fin de visualizar a las representaciones de las y los escolares respecto a su entorno (Salas, 2011).

La escuela elegida es de la zona norponiente de la Región Metropolitana en Chile, la cual está calificada como vulnerable en base a los índices económicos de su alumnado. De esta manera, cuenta con un convenio de subvención escolar preferencial, recibiendo aportes económicos especiales, pero en directa relación con los estudiantes chilenos vulnerables. 
Del total de la población chilena actual, el $24.2 \%$ son niñas, niños y adolescentes entre los o y 17 años. De ellos, el 2.8 son migrantes; pero si se considera solo la población escolar que asiste a la educación municipal, este porcentaje sube al 4.5\% (Unicef, 2020). En este sentido, observar cómo son representados las y los estudiantes migrantes en una escuela básica, puede arrojar luces importantes para el trabajo de la convivencia intercultural en el aula.

\section{Representaciones sociales}

Existe consenso en entender a la representación social como un proceso de conocimiento basado en un acuerdo tácito y de sentido común de un grupo sociocultural para acceder a las nuevas dimensiones que la realidad entrega (Abric, 1994; Jodelet, 1986; Moscovici, 1979). La propia comunidad va construyendo a través de la comunicación sobre algo o alguien un saber común, no experto, pero sí social y funcional. La realidad es interpretada por las personas de una u otra forma según las herramientas básicas de conocimiento de que dispongan. Ciertamente una representación social sobre un grupo de individuos no será necesariamente objetiva ni exhaustiva, pero le permite a quienes generan esa representación acercarse al nuevo ámbito de la realidad que exploran y conceptualizan para actuar frente a ella. Dice Moscovici (1979), autor que acuñó dicha expresión:

La representación social es un corpus organizado de conocimientos y una de las actividades psíquicas gracias a las cuales los hombres hacen inteligible la realidad física y social, se integran en un grupo o en una relación cotidiana de intercambios, liberan los poderes de su imaginación. (p. 18)

Las representaciones sociales se elaboran socialmente a través de la comunicación de unos y otros, lo cual conlleva a que estas orienten también los actuares de los sujetos de la comunidad. Sin embargo, los grupos sociales no actúan sin alguna motivación excepcional, sino cuando ocurren hechos nuevos en su entorno que necesitan conocer. En el pensamiento de Moscovici, destaca Mora (2002), se perfilan tres condiciones de emergencia: dispersión de la información, focalización y presión de la inferencia. La primera se refiere a que la información que entrega el objeto de representación no es suficiente y suele estar desorganizada; la segunda se refiere a que este objeto que se representa está implicado en interacciones sociales complejas; y, por último, la tercera condición se presenta porque la sociedad exige saber, entender, opinar y clarificar el nuevo objeto social que llega a su realidad. Plantea Moscovici (1979): «En la vida corriente, las circunstancias y las relaciones sociales exigen del individuo o del grupo social que sea capaz, en todo 
momento, de actuar, de tomar posición. En una palabra, se debe estar en situación de responder» (p. 178). Entonces, para Moscovici la representación social es una respuesta colectiva a un evento que pide y exige ser conocido. Si este objeto se conoce desde lo negativo o desde lo positivo, no es posible controlarlo desde el mismo hecho social. De tal manera, el esquema cognoscitivo del objeto representado se va desarrollando desde el sentido común y desde la comunicación natural del grupo social que forma universos de opinión.

El estudio de las representaciones sociales permite acceder, no solo a ver la forma en que una comunidad social sistematiza la realidad, sino también permite observar si esas formas son positivas o negativas, si generan una justa convivencia social o no. Cuevas (2016), también teniendo como referente base la obra de Moscovici, realiza un mapeo general sobre los estudios de representación social en las investigaciones educativas y destaca que «un objeto de estudio sobre representaciones sociales tiene que reunir tres elementos: un objeto de representación, un sujeto que construye la representación social y un contexto particular en el que surge la representación» (p. 115). De esta forma, el objeto de representación es motivo de alteración, discusión y replanteo de la realidad recurrentemente en el entorno social que se presenta; el sujeto de representación es aquel que se sitúa en una coordenada temporal y espacial relacionándose con los otros; mientras que el contexto es un tiempo y un espacio donde surgen las representaciones bajo condiciones socioeconómicas e históricas que presentan algún nivel de crisis (Moscovici, 1979; Páez, 1987). Las condiciones de emergencia descritas por Mora y los elementos destacados por Cuevas nos permiten sistematizar el abordaje de este estudio en la escuela elegida para observar la dinámica de la representación social.

\section{Objeto de representación}

En esta investigación el objeto de representación son las y los niños migrantes, específicamente, los estudiantes haitianos de una escuela pública de la zona norponiente de la ciudad de Santiago de Chile, cuyos padres llegan principalmente en búsqueda de oportunidades laborales. Este objeto de representación es motivo de replanteo de la realidad recurrentemente en el entorno social de la escuela. Se advierte que el grupo migrante llegado a las escuelas públicas chilenas es un tema complejo para los docentes, quienes no cuentan con herramientas teóricas ni metodológicas para realizar didácticas inclusivas en interculturalidad, ni mucho menos en la integración de una segunda lengua (Campos, 2019) pero también es complejo y desconocido para las y los estudiantes chilenos que 
comparten la realidad escolar. Quienes llegan traen un nuevo color de piel, una nueva lengua, nuevos juegos, comidas, música y nuevas representaciones del mundo escolar.

\section{Sujeto de representación}

El sujeto de representación es el grupo de estudiantes chilenos de $1^{\underline{0}}$ a $8^{\underline{o}}$ básico, entre los 6 y 15 años de edad que convive en la escuela con los y las estudiantes migrantes. El entramado de la escuela perfila a este sujeto de representación y le da voz, pero no conciencia de la relevante organización que realiza de la nueva realidad que le toca vivir. Es decir, el sujeto de representación es tan inocente como el objeto de presentación que se da en el aula multicultural que se observa. Objeto y sujeto interactúan sin mayores orientaciones sobre el proceso intercultural que se vive. Se evidencia que el sujeto de representación es mayor en número, pero tan ajeno a la complejidad social que vive como el objeto de su representación.

\section{Contexto}

En el caso de este estudio, el tiempo en el que se encuesta a las y los estudiantes corresponde al 2018. El lugar, como ya se dijo, es una escuela de Santiago de Chile ubicada en un barrio pobre de condiciones precarias en cuanto a la vivienda, la vialidad y las atenciones de salud. Tal como lo plantea Silva et al. (2018), esta zona periférica tiene las mismas características del proyecto urbanístico latinoamericano donde el riesgo social y ambiental es desequilibradamente mayor que en la zona central de Santiago; sin embargo, la población migrante es cada vez más significativa en esta zona, pues encuentra espacios donde puede hacer su vida. Paradójicamente, este proceso va incrementando la población desfavorecida de la ciudad de Santiago. La escuela es municipal, de educación parvularia y básica. Cuenta con aproximadamente 450 estudiantes, siendo de acceso gratuito. Esta escuela ha tenido un aumento sostenido año a año en el ingreso de estudiantes extranjeros, en especial desde Haití.

\section{Método}

La investigación se aborda desde una perspectiva cuantitativa y descriptiva, utilizando como instrumento fundamental a la encuesta; esta alcanza de modo eficiente los datos que se quieren observar, puesto que lo importante es la información que se obtiene del total de sujetos encuestados y no de las particularidades de los individuos (Casas, 2003). 
El estudio se diseñó en tres etapas: exploración, aplicación y análisis. En la etapa exploratoria se diseñó el instrumento a partir de cuatro temas clave. Luego se aplicó una primera vez a manera de pilotaje a un grupo de estudiantes en una escuela del mismo perfil sociocultural. Se detectó que las preguntas de respuestas cerradas de apreciación tenían mejor recepción que las preguntas abiertas, pues en estas últimas la tendencia fue no contestar todo. Finalmente se ajustó la gramática y el léxico de algunas preguntas con el fin de utilizar frases coloquiales para las y los escolares comprendieran a cabalidad la encuesta.

En la etapa de aplicación lo primero que se realizó fue visitar la escuela elegida un par de semanas antes de encuestar con el fin de realizar prácticas de acercamiento a través de juegos que permitieran al estudiantado conocer a los encuestadores y así cautelar que niños, niñas y adolescentes se sintieran cómodos con esta tarea y pudieran oponerse si así lo hubieran querido. Todos los y las escolares aceptaron responder la encuesta el día que se aplicó, contestando de forma anónima y participativa. Por otra parte, el equipo docente y directivo solicitó formalmente la autorización de los apoderados para esta investigación con el fin de resguardar de los derechos de niños, niñas y adolescentes (Ravetllat, 2017; Silva et al., 2018; Vergara, 2015).

En la etapa de análisis se focalizaron las variables del estudio y se ordenaron en una estadística descriptiva que permitiera inferir las formas generales de representación social que las y los escolares utilizan para referirse al estudiantado haitiano.

Para la muestra se seleccionó una escuela pública de la comuna de Quilicura en la Región Metropolitana en Chile. Quilicura concentra altos índices de matrícula haitiana en sus escuelas. Cuenta en su política educativa con una mirada de acogida y fue la primera comuna en recibir el Sello Migrante en el año 2015 como reconocimiento estatal por su interés explícito en abrir los espacio de diálogo intercultural (Castillo et al., 2018; Thayer, 2014).

La encuesta se aplicó en toda la enseñanza básica de la escuela estudiada, sin exclusión de cursos ni estudiantes; sin embargo, de un universo total de 450 matriculados, el día de la encuesta solo asistieron 282 estudiantes. La inasistencia es un problema constante en la educación pública chilena (Castro \& Rivas, 2006; Espinoza-Díaz et al., 2014). En consecuencia, las encuestas logradas se validaron como representativas. Del total de las encuestas obtenidas, 213 corresponden a estudiantes chilenos, 58 a estudiantes haitianos y 11 a estudiantes migrantes del resto de Latinoamérica (6 peruanos, dos bolivianos, un ecuatoriano, un colombiano y un brasileño). 
La encuesta utilizada contó con 11 preguntas, de las cuales nueve fueron cerradas para tres respuestas posibles: sí, no, más o menos. Este tipo de preguntas busca conocer representaciones valorativas de aceptación o rechazo frente al alumnado migrante. Las otras dos preguntas fueron abiertas de respuesta corta, a fin de obtener información precisa del conocimiento de la realidad migrante del alumnado chileno.

Las variables definidas para el estudio son el nivel escolar según la edad y el género del alumnado. Observar con atención el género es importante pues las sociedades escolares también reproducen el sistema de jerarquía y dicotomía en que lo femenino se percibe como sensible, débil y emocional, mientras que lo masculino como fuerte, rebelde e indiferente, entre otras características (Moreno et al., 2017; De Piero, 2018).

Los temas encuestados fueron los siguientes:

1. Apreciación de Chile como país receptor de migrantes (2 preguntas cerradas).

2. Apreciación de Haití como país de origen migratorio (2 preguntas cerradas).

3. Apreciación de otra lengua, otra mirada del mundo (2 preguntas cerradas y una pregunta abierta).

4. Apreciaciones generales sobre la realidad intercultural (3 preguntas cerradas y una pregunta abierta).

Las temáticas se definieron por ser las más cercanas a la conversación del día a día en la escuela; además contaron con la aprobación del grupo directivo y docente de la institución escolar que aceptó esta investigación.

Se definieron también tres grupos de estudiantes: estudiantes chilenos, estudiantes llegados desde Haití y estudiantes del resto de Latinoamérica. El grupo de estudiantes haitianos recibió la encuesta en español y en creole para elegir en qué lengua responder; así, de los 58 estudiantes haitianos, el $47 \%$ respondió en creole y el $53 \%$ en español. Desde $1^{\circ}$ a $4^{\circ}$ básico ( 6 a 9 años), la escuela estudiada tiene dos cursos por nivel, y desde $5^{\circ}$ a $8^{\mathrm{o}}$ básico (10 a 15 años), solo uno. No obstante lo anterior, desde $1^{\underline{0}}$ a $4^{\underline{0}}$ se contabilizan 107 estudiantes y desde $5^{\circ}$ a $8^{\underline{0}}$ año, 106 .

Respecto al perfil de la educación básica es necesario mencionar que las y los alumnos que cursan de $1^{\underline{0}}$ a $4^{\underline{0}}$ básico tienen como característica ser guiados por un mismo profesor en la mayoría de las asignaturas, por lo que el acompañamiento y la cohesión del grupo es significativa. Los alumnos de $5^{\underline{0}}$ a $8^{\circ}$ básico tienen diferentes profesores en sus asignaturas. Junto con esto, comienzan una serie de cambios sicológicos y físicos debidos 
a la preadolescencia. En este contexto, el estudio entregó resultados en relación a los y las escolares de $1^{\underline{0}}$ a $4^{\underline{0}}$ básico y de $5^{\underline{0}}$ a $8^{\circ}$ año básico. En Chile estos segmentos escolares se conocen como primer y segundo ciclo básico. Para los efectos de este estudio, se abordarán solo los resultados de la encuesta realizada a los 216 estudiantes chilenos, pues son ellos quienes generan la representación social de sus compañeros y compañeras de Haití.

En cuanto a edades y género del universo de estudiantes chilenos y haitianos encuestados, estos se pueden apreciar las tablas 1 y 2.

\section{Tabla 1}

Número de estudiantes chilenos por edad y género

\begin{tabular}{lccc}
\hline Edad & Cantidad & Género masculino & Género femenino \\
\hline 6 años (primer ciclo) & 11 & 4 & 7 \\
7 años (primer ciclo) & 24 & 13 & 11 \\
8 años (primer ciclo) & 43 & 17 & 26 \\
9 años (primer ciclo) & 29 & 14 & 15 \\
10 años (segundo ciclo) & 15 & 10 & 5 \\
11 años (segundo ciclo) & 26 & 14 & 12 \\
12 años (segundo ciclo) & 21 & 13 & 8 \\
13 años (segundo ciclo) & 23 & 12 & 11 \\
14 años (segundo ciclo) & 13 & 7 & 6 \\
15 años (segundo ciclo) & 8 & 2 & 6 \\
Total & $\mathbf{2 1 3}$ & 106 & 107 \\
\hline
\end{tabular}

Tabla 2

Número de estudiantes haitianos por edad y género

\begin{tabular}{lccc}
\hline Edad & Cantidad & Género masculino & Género femenino \\
\hline 6 años (primer ciclo) & 7 & 6 & 1 \\
7 años (primer ciclo) & 8 & 3 & 5 \\
8 años (primer ciclo) & 6 & 2 & 4 \\
9 años (primer ciclo) & 8 & 3 & 5 \\
10 años (segundo ciclo) & 4 & 2 & 2 \\
11 años (segundo ciclo) & 11 & 6 & 5 \\
12 años (segundo ciclo) & 8 & 5 & 3 \\
13 años (segundo ciclo) & 2 & 1 & 1 \\
14 años (segundo ciclo) & 4 & 2 & 2 \\
15 años (segundo ciclo) & 0 & 0 & 0 \\
Total & $\mathbf{5 8}$ & $\mathbf{3 0}$ & $\mathbf{2 8}$ \\
\hline
\end{tabular}


En términos generales, se observa que la distribución de género es similar en los grupos chileno y haitiano. También se destaca que en el grupo de escolares chilenos se produce una acumulación notable en los 8 años, siendo en este caso mayor el número de niñas. Es equilibrado el número de escolares en cada ciclo del alumnado chileno, pues de $1^{\underline{0}}$ a $4^{\underline{O}}$ básico se contabilizan 107 estudiantes y de $5^{\underline{0}}$ a $8^{\circ}$ año, 106. En el grupo del estudiantado haitiano en cada ciclo se contabilizan 29 encuestados.

Si bien la enseñanza básica en Chile termina habitualmente a los 13 años, muchos estudiantes deben repetir el curso para cumplir los objetivos curriculares; por lo tanto, en este estudio también se incluyen a los y las estudiantes de 14 y 15 años. Por otro lado, el estudiantado haitiano que llega al sistema educativo chileno, ${ }^{1}$ es integrado a cada curso según su edad y no respecto a su manejo de la lengua española o al nivel de los conocimientos curriculares.

\section{Resultados}

Los resultados se organizan de acuerdo a los cuatro ítems encuestados y se abordan desde las variables de nivel escolar según edad y de género.

\section{Ítem I. Apreciación de Chile como país receptor}

En este ítem se buscaba conocer las representaciones de aceptación o rechazo que el alumnado chileno tiene de su propio país como un lugar receptor de personas migrantes. También se examinó la propia escuela como espacio de residencia para estudiantes extranjeros. Con estos propósitos, se realizaron dos preguntas: ¿te gusta que vengan a vivir a Chile personas de otros países?, y ite gusta tener compañeros y compañeras que vienen de otros países? Los resultados se exponen en la tabla 3 .

\footnotetext{
${ }^{1}$ El sistema escolar chileno contempla tres etapas obligatorias: educación parvularia ( 4 y 5 años de edad), educación básica (desde los 6 a los 13 años de edad) y educación media (desde los 14 a los 18 años). En la educación básica se denomina primer ciclo a los cursos primero, segundo, tercero y cuarto. El segundo ciclo está formado por los cursos quinto, sexto, séptimo y octavo.
} 


\section{Tabla 3}

Variables frente a las preguntas n. ${ }^{\circ} 1$ y n. ${ }^{\circ} 2$ del ítem I

\section{Respuesta afirmativa para la pregunta $n .^{\circ} 1$ : ¿Te gusta que vengan a vivir a Chile personas de otros países?}

$100 \%$ de estudiantes que responden afirmativamente. Universo de 119 escolares.

\section{$50.5 \%$ género masculino} $49.5 \%$ género femenino $74 \%$ cursan de $1^{\circ}$ a $4^{\circ}$ básico

$26 \%$ cursan de $5^{\circ}$ a $8^{\circ}$ básico
Respuesta afirmativa para la pregunta $n .^{\circ} 2$ : ¿Te gusta tener compañeros y compañeras que vienen de otros países?

$100 \%$ de estudiantes $52 \%$ género masculino que responden afirmativamente.

Universo de 128

escolares.
$48 \%$ género femenino

$72 \%$ cursan de $1^{\circ}$ a $4^{\circ}$ básico

$28 \%$ cursan de $5^{\circ}$ a $8^{\circ}$ básico
Respuesta negativa para la pregunta $n .^{\circ} 1$ : ¿Te gusta que vengan a vivir a Chile personas de otros países?

$100 \%$ de estudiantes que responden negativamente.

Universo de 32 escolares.
$48 \%$ género masculino

$52 \%$ género femenino $58 \%$ cursan de $1^{\circ}$ a $4^{\circ}$ básico $42 \%$ cursan de $5^{\circ}$ a $8^{\circ}$ básico
Respuesta negativa para la pregunta $n .^{\circ} 2$ : ¿Te gusta tener compañeros y compañeras que vienen de otros países?

$100 \%$ de estudiantes $60 \%$ género masculino que responden negativamente.

Universo de 19

$40 \%$ género femenino

$80 \%$ cursan de $1^{\circ}$ a $4^{\circ}$ básico

escolares.

$20 \%$ cursan de $5^{\circ}$ a $8^{\circ}$ básico

Respuesta más o menos para la pregunta $n .^{\circ} 1$ : Respuesta más o menos para la pregunta $n .^{\circ} 2$ : $¿$ Te gusta que vengan a vivir a Chile personas de otros países? ¿Te gusta tener compañeros y compañeras que vienen de otros países?

$100 \%$ de estudiantes que responden más o menos.

Universo de 62 escolares.
$55 \%$ género masculino

$45 \%$ género femenino

$26 \%$ cursan de $1^{\circ}$ a $4^{\circ}$ básico

$74 \%$ cursan de $5^{\circ}$ a $8^{\circ}$ básico
$100 \%$ de estudiantes que responden más o menos.

Universo de 66 escolares.
$48 \%$ género masculino

$52 \%$ género femenino

$23 \%$ cursan de $1^{\circ}$ a $4^{\circ}$ básico

$77 \%$ cursan de $5^{\circ}$ a $8^{\circ}$ básico

Destaca, en primer lugar, que sobre el 54\% (119 estudiantes) acepta la llegada de migrantes al país y el 60\% (128 estudiantes) a la sala de clases. Frente a estos datos, cabe destacar lo investigado por Castillo et al. (2018), quienes observan que, a mayor población migrante en las escuelas, mayor es la aceptación de las y los estudiantes nacionales. El autor recoge un artículo de Thayer (2014) quien ya había detectado este fenómeno en escuelas españolas. Ahora bien, como se aprecia en la tabla 3, la mayor aceptación del estudiantado nacional es transversal en relación a la variable género, pero no frente a la variable nivel escolar; así, quienes cursan de $1^{\underline{O}}$ a $4^{\underline{o}}$ básico triplican en su aceptación a los estudiantes desde $5^{\underline{0}}$ a $8^{\underline{o}}$ año.

La escuela estudiada recibe mayor alumnado haitiano en el primer ciclo, según las referencias oficiales de matrícula, aún cuando para el día de la encuesta haya habido cantidades promedio comparables en ambos ciclos básicos. En este sentido, escolares nacionales

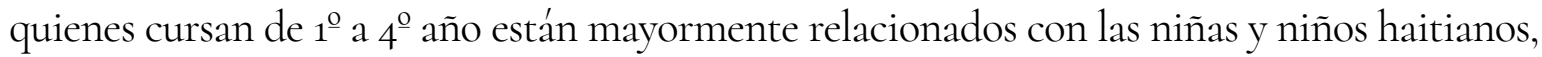


por lo que la representación social se construye con menos distancia corporal entre el sujeto y el objeto de representación (Cuevas, 2016). Además, como lo plantean Vergara et al. (2015), «las personas no construyen sus pensamientos en aislamiento, sino que se influyen unas a otras sobre la base de las verificaciones colectivamente compartidas, referidas a los objetos que conforman su realidad» (p. 58). Claramente, la proximidad física de escolares nacionales y migrantes permite la circulación de juegos, saberes, emociones e ideas que permiten las negociaciones de sentido de la realidad y, consecuentemente, se abren los espacios al diálogo intercultural (Amán, 2012; Medina \& Carreño, 2015; Unesco, 2009)

\section{Ítem II. Apreciación de Haití como país de origen migratorio}

En este ítem se quiere conocer la representación de valoración que las y los escolares chilenos generan sobre Haití como país desde donde emigra el estudiantado haitiano. Se realizan dos preguntas: ¿conoces la historia de Haití?, y ¿te gustaría visitar Haití?, cuyos resultados se exponen en la tabla 4 .

Tabla 4

Variables frente a las preguntas n. ${ }^{\circ} 1$ y n. .0 del item II

\begin{tabular}{|c|c|c|c|}
\hline \multicolumn{2}{|c|}{$\begin{array}{c}\text { Respuesta positiva a la pregunta } n .^{\circ} 1: \\
¿ \text { ¿Conoces la historia de Haití? }\end{array}$} & \multicolumn{2}{|c|}{$\begin{array}{c}\text { Respuesta positiva a la pregunta } n .^{\circ} 2 \text { : } \\
\text { ¿Te gustaría visitar Haití? }\end{array}$} \\
\hline \multirow{4}{*}{$\begin{array}{l}100 \% \text { de } \\
\text { estudiantes que } \\
\text { responden } \\
\text { positivamente. } \\
\text { Universo de } 27 \\
\text { escolares. }\end{array}$} & 41 \% género masculino & \multirow{4}{*}{$\begin{array}{l}100 \% \text { de estudiantes } \\
\text { que responden } \\
\text { positivamente. } \\
\text { Universo de } 87 \\
\text { escolares. }\end{array}$} & 49 \% género masculino \\
\hline & $59 \%$ & & $51 \%$ \\
\hline & 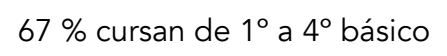 & & 7 \\
\hline & $\%$ cursa & & 249 \\
\hline \multicolumn{2}{|c|}{$\begin{array}{c}\text { Respuesta negativa la pregunta } n .^{\circ} 1: \\
\text { ¿Conoces la historia de Haití? }\end{array}$} & \multicolumn{2}{|c|}{$\begin{array}{c}\text { Respuesta negativa la pregunta } n .^{\circ} 2: \\
\text { ¿Te gustaría visitar Haití? }\end{array}$} \\
\hline \multirow{4}{*}{$\begin{array}{l}100 \% \text { de } \\
\text { estudiantes que } \\
\text { responden } \\
\text { negativamente. } \\
\text { Universo de } 175 \\
\text { escolares. }\end{array}$} & $\% \varsigma$ & \multirow{4}{*}{$\begin{array}{l}100 \% \text { de estudiantes } \\
\text { que responden } \\
\text { negativamente. } \\
\text { Universo de } 91 \\
\text { escolares. }\end{array}$} & 0 \\
\hline & $\%$ & & $46 \%$ \\
\hline & $57 \%$ cursan & & $48 \%$ cursan de $1^{\circ}$ a $4^{\circ}$ bá \\
\hline & $5^{\circ}$ a $8^{\circ}$ básico & & $52 \%$ cursan de $5^{\circ}$ a $8^{\circ}$ básico \\
\hline
\end{tabular}

Respuesta más o menos a la pregunta $n .^{\circ} 1$ : Respuesta más o menos a la pregunta $n .^{\circ} 2$ : ¿Conoces la historia de Haití? ¿Te gustaría visitar Haití?

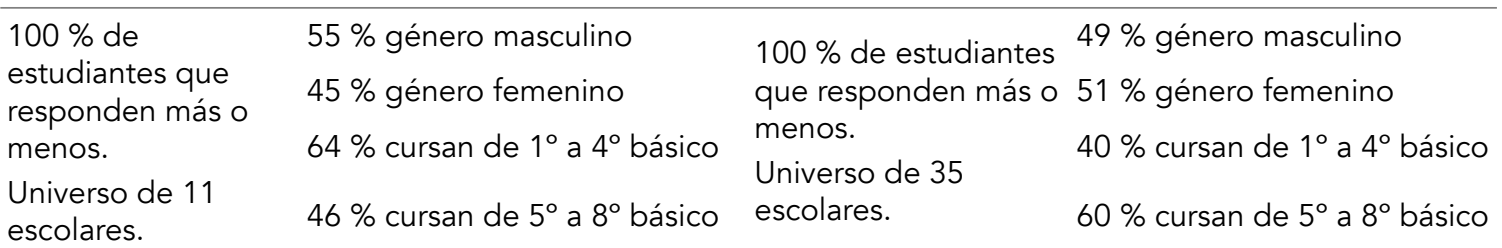


El primer dato relevante de este ítem es que el $82 \%$ de los encuestados ( 175 escolares) dice no conocer la historia de Haití, de forma transversal en las dos variables estudiadas. De tal manera, el concepto de invisibilización del sujeto migrante se hace patente (Bastidas \& Torrealba, 2014; Mora, 2018), pues en una escuela en donde hay gran cantidad de niños, niñas y adolescentes haitianos, es difícil entender que la mayoría del alumnado nacional diga no conocer del lugar de origen de sus compañeras y compañeros extranjeros. Acá se produce la deslegitimación simbólica de la identidad de las y los escolares de origen haitiano, en tanto que implica un rechazo silencioso. Stefoni et al. (2016) exponen que el racismo y la discriminación tienen formas simuladas y encubiertas que desaparecen al migrante: «se trataría de una forma de racismo negada, invertida, autorreferencial, que dice respetar la identidad de un otro, pero a una distancia que le permite su posición universal privilegiada» (p. 157). Esto no necesariamente es comprendido en el ámbito escolar por los sujetos que representan al estudiantado migrante; más bien es una naturalización de prácticas que no se cuestionan ni se abordan críticamente, por lo cual se repiten desde los marcos oficiales del Estado (Mendoza \& Lazzaro-Salazar, 2019) hasta la convivencia más sencilla entre escolares en una sala de clase.

Cabe destacar al 40\% (87) de escolares quienes quisieran visitar Haití. Nuevamente, la variable género se muestra equitativa y la variable nivel escolar expone mayor aceptación en quienes cursan del $1^{\underline{0}}$ al $4^{\underline{0}}$ año básico.

\section{Ítem III. Apreciación de otra lengua: otra mirada del mundo}

En este ítem se realizaron tres preguntas (dos cerradas y una abierta) con el fin de conocer la representación valorativa que el alumnado nacional tiene de la lengua creole que escuchan en la escuela. Las preguntas fueron: ¿te gusta que algunos compañeros hablen otra lengua diferente al español?, ¿cómo se llama la lengua que hablan tus compañeras y compañeros haitianos?, y ¿te gustaría aprender creole, la lengua de Haití? Los resultados se exponen en la tabla 5 . 
Tabla 5

Variables frente a las preguntas $n .{ }^{\circ} 1$ y $n .^{\circ} 3$ del ítem III

\begin{tabular}{|c|c|c|c|}
\hline \multicolumn{2}{|c|}{$\begin{array}{l}\text { Respuesta positivamente la pregunta } n .^{\circ} 1: \\
\text { ¿Te gusta que algunos compañeros hablen otra } \\
\text { lengua, diferente al español? }\end{array}$} & \multicolumn{2}{|c|}{$\begin{array}{c}\text { Respuesta positivamente la pregunta } \text { n. }^{\circ} 3 \text { : } \\
\text { ¿Te gustaría aprender creole, la lengua de } \\
\text { Haití? }\end{array}$} \\
\hline \multirow{4}{*}{$\begin{array}{l}100 \% \text { de estudiantes } \\
\text { que responden } \\
\text { positivamente. } \\
\text { Universo de } 94 \\
\text { escolares. }\end{array}$} & $9 \%$ & \multirow{4}{*}{$\begin{array}{l}100 \% \text { de estudiantes } \\
\text { que responden } \\
\text { positivamente. } \\
\text { Universo de } 132 \\
\text { escolares. }\end{array}$} & \\
\hline & 61 \% género femenino & & $52 \%$ género \\
\hline & $72 \%$ & & 689 \\
\hline & $28 \%$ & & 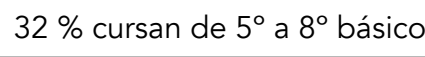 \\
\hline \multicolumn{2}{|c|}{$\begin{array}{l}\text { Respuesta negativa la pregunta } n .^{\circ} 1: \\
\text { ¿Te gusta que algunos compañeros hablen otra } \\
\text { lengua, diferente al español? }\end{array}$} & \multicolumn{2}{|c|}{$\begin{array}{c}\text { Respuesta negativa la pregunta } \mathrm{n}^{\circ} 3 \text { : } \\
\text { ¿Te gustaría aprender creole, la lengua de } \\
\text { Haití? }\end{array}$} \\
\hline \multirow{4}{*}{$\begin{array}{l}100 \% \text { de estudiantes } \\
\text { que responden } \\
\text { negativamente. } \\
\text { Universo de } 64 \\
\text { escolares. }\end{array}$} & & \multirow{4}{*}{$\begin{array}{l}100 \% \text { de estudiantes } \\
\text { que responden } \\
\text { negativamente. } \\
\text { Universo de } 54 \\
\text { escolares. }\end{array}$} & \\
\hline & $42 \%$ & & 4 \\
\hline & ${ }^{\circ}$ a $4^{\circ}$ & & $52 \%$ \\
\hline & $44 \%$ cursan de $5^{\circ}$ a $8^{\circ}$ básico & & 48 \\
\hline \multicolumn{2}{|c|}{$\begin{array}{l}\text { Respuesta más o menos a la pregunta } n .^{\circ} 1: \\
\text { ¿Te gusta que algunos compañeros hablen otra } \\
\text { lengua, diferente al español? }\end{array}$} & \multicolumn{2}{|c|}{$\begin{array}{c}\text { Respuesta más o menos a la pregunta } n .^{\circ} 3: \\
\text { ¿Te gustaría aprender creole, la lengua de } \\
\text { Haití? }\end{array}$} \\
\hline \multirow{3}{*}{$\begin{array}{l}100 \% \text { de estudiantes } \\
\text { que responden más o } \\
\text { menos. } \\
\text { Universo de } 51 \\
\text { escolares. }\end{array}$} & 5 \% género masculino & \multirow{3}{*}{$\begin{array}{l}100 \% \text { de estudiantes } \\
\text { que responden más o } \\
\text { menos. } \\
\text { Universo de } 27 \\
\text { escolares. }\end{array}$} & $59 \%$ \\
\hline & erromentino & & $41 \%$ género femenino \\
\hline & $\begin{array}{l}31 \% \text { cursan de } 1^{\circ} \text { a } 4^{\circ} \text { básico } \\
69 \% \text { cursan de } 5^{\circ} \text { a } 8^{\circ} \text { básico }\end{array}$ & & $\begin{array}{l}26 \% \text { cursan de } 1^{\circ} \text { a } 4^{\circ} \text { básico } \\
74 \% \text { cursan de } 5^{\circ} \text { a } 8^{\circ} \text { básico }\end{array}$ \\
\hline
\end{tabular}

En primer lugar, se distingue que, frente a la pregunta 3, el 62\% (132 escolares) declara afirmativamente querer aprender creole. La variable género es equiparable, pero son las y los escolares de $1^{\underline{0}}$ a $4^{\underline{0}}$ año quienes presentan mayor interés. Este mismo nivel escolar destaca en la valoración positiva frente a la pregunta 1; aquí son las escolares de género femenino quienes destacan. En cuanto a las respuestas negativas a las preguntas 1 y 3 , se advierte que los estudiantes de género masculino presentan el mayor rechazo; por último, se advierte en el nivel escolar de $5^{\underline{0}}$ a $8^{\underline{0}}$ la mayor indecisión frente a las preguntas realizadas, siendo de género masculino quienes componen principalmente este grupo.

Una lengua diferente en la sala de clases se ve como un problema y no como un aporte (Campos, 2019; Muñoz, 200o; Pavez-Soto et al., 2019). Aun cuando el Estado de Chile está, finalmente, impulsando el respeto por las lenguas indígenas (Programa de Educación Intercultural Bilingüe), no ha logrado lo mismo con las lenguas migrantes, lo cual no es privativo de Chile sino un olvido que se produce también en otros países latinoamericanos (Higuera \& Castillo, 2015; Pavez-Soto et al., 2018). Ante este panorama, el 
interés de niñas, niños y adolescentes chilenos por aprender creole es una luz en los procesos de apreciación y respeto intercultural.

Frente a la pregunta 2, de tipo abierta y respuesta corta (¿cómo se llama la lengua que hablan tus compañeras y compañeros haitianos?) el 70 \% (149 estudiantes) contestó creole. Las variables de mayor presencia fueron el género femenino y el primer ciclo básico. Hubo un $26 \%$ del alumnado que no responde o responde que no sabe, mientras el restante $4 \%$ respondió: chileno, haitiano o francés. En este ítem se revierte la invisibilización respecto a la historia de Haití y el alumnado nacional se abre al reconocimiento de una nueva lengua en la sala de clases. Este hecho es un punto de partida para la convivencia de culturas distintas pero igualmente valoradas.

\section{Îtem IV. Apreciaciones generales de la realidad intercultural}

Para este ítem se realizaron tres preguntas (dos cerradas y una abierta) de respuesta corta: ¿te gusta tu escuela con compañeros y compañeras de otros países?, ¿has visto en tu escuela situaciones de maltrato a niñas y niños extranjeros?, y ¿qué es lo que más te llama la atención de tus compañeras y compañeros extranjeros? Los resultados se exponen en la tabla 6.

Del universo de 213 estudiantes, el 84\% (178 escolares) manifiesta que le gusta su escuela con alumnado migrante; una vez más sobresalen quienes cursan el primer ciclo básico. Solo el $3 \%$ dice que no le gusta la escuela con migrantes. Por otro lado, el 54\% (116 escolares) dice haber visto situaciones de maltrato a niños y niñas migrantes; pero el $37 \%$ ( 78 escolares), en su mayoría de $1^{\underline{0}}$ a $4^{\underline{Q}}$ año, dicen no haber visto maltrato.

Por un lado, se observa una apertura importante del alumnado nacional frente al alumnado migrante, lo cual es positivo sin duda alguna. Los estudios sobre el racismo y discriminación de la población chilena (Mendoza \& Lazzaro-Salazar, 2019; Tijoux \& Díaz, 2014) indican que las personas adultas se autodefinen como racistas y discriminadores frente a los extranjeros piel oscura, con un ideal homogéneo y sobrevalorado de lo blanco (Tijoux, 2013). Sin embargo, las y los estudiantes nacionales logran presentar un juicio crítico más favorable con quienes comparten la sala de clases. 
Tabla 6

Variables frente a las preguntas $n .{ }^{o} 1$ y $n . .^{o} 2$ del ítem IV

\begin{tabular}{|c|c|c|c|}
\hline \multicolumn{2}{|c|}{$\begin{array}{l}\text { Respuesta positiva a la pregunta } n^{\circ} 1 \text { : } \\
\text { ¿Te gusta tu escuela con compañeros y } \\
\text { compañeras de otros países? }\end{array}$} & \multicolumn{2}{|c|}{$\begin{array}{l}\text { Respuesta positiva a la pregunta } n^{\circ} 2 \text { : } \\
\text { ¿Has visto en tu escuela situaciones de } \\
\text { maltrato a niñas y niños extranjeros? }\end{array}$} \\
\hline \multirow{2}{*}{$\begin{array}{l}100 \% \text { de estudiantes } \\
\text { que responden } \\
\text { positivamente. }\end{array}$} & 49 \% género masculino & \multirow{2}{*}{$\begin{array}{l}100 \% \text { de estudiantes } \\
\text { que responden } \\
\text { positivamente. }\end{array}$} & 53 \% género masculino \\
\hline & 51 \% género femenino & & $47 \%$ género femenino \\
\hline \multirow{2}{*}{$\begin{array}{l}\text { Universo de } 178 \\
\text { escolares. }\end{array}$} & $60 \%$ cursan de $1^{\circ}$ a $4^{\circ}$ básico & \multirow{2}{*}{$\begin{array}{l}\text { Universo de } 116 \\
\text { escolares. }\end{array}$} & $56 \%$ cursan de $1^{\circ}$ a $4^{\circ}$ básico \\
\hline & $40 \%$ cursan de $5^{\circ}$ a $8^{\circ}$ básico & & $44 \%$ cursan de $5^{\circ}$ a $8^{\circ}$ básico \\
\hline \multicolumn{2}{|c|}{$\begin{array}{l}\text { Respuesta negativa a la pregunta } n .^{\circ} 1: \\
\text { ¿Te gusta tu escuela con compañeros y } \\
\text { compañeras de otros países? }\end{array}$} & \multicolumn{2}{|c|}{$\begin{array}{l}\text { Respuesta negativa a la pregunta } n .^{\circ} 2: ~ ¿ \text { Has } \\
\text { visto en tu escuela situaciones de maltrato a } \\
\text { niñas y niños extranjeros? }\end{array}$} \\
\hline \multirow{2}{*}{$\begin{array}{l}100 \% \text { de estudiantes } \\
\text { que responden } \\
\text { negativamente. }\end{array}$} & $67 \%$ género masculi & \multirow{2}{*}{$\begin{array}{l}100 \% \text { de estudiantes } \\
\text { que responden } \\
\text { negativamente. }\end{array}$} & 50 \% géne \\
\hline & 33 \% género femenino & & 50 \% género femenino \\
\hline \multirow{2}{*}{$\begin{array}{l}\text { Universo de } 6 \\
\text { escolares. }\end{array}$} & $0 \%$ cursan de $1^{\circ}$ a $4^{\circ}$ básico & \multirow{2}{*}{$\begin{array}{l}\text { Universo de } 78 \\
\text { escolares. }\end{array}$} & $62 \%$ cursan de $1^{\circ}$ a $4^{\circ}$ básico \\
\hline & $100 \%$ cursan de $5^{\circ}$ a $8^{\circ}$ básico & & $38 \%$ cursan de $5^{\circ}$ a $8^{\circ}$ básico \\
\hline \multicolumn{2}{|c|}{$\begin{array}{c}\text { Respuesta más o menos a la pregunta } \mathrm{n}^{\circ}{ }^{1:} \\
\text { ¿Te gusta tu escuela con compañeros y } \\
\text { compañeras de otros países? }\end{array}$} & \multicolumn{2}{|c|}{$\begin{array}{l}\text { Respuesta más o menos a la pregunta } n .^{\circ} 2: \\
\text { ¿Has visto en tu escuela situaciones de } \\
\text { maltrato a niñas y niños extranjeros? }\end{array}$} \\
\hline \multirow{2}{*}{$\begin{array}{l}100 \% \text { de estudiantes } \\
\text { que responden más o } \\
\text { menos. }\end{array}$} & $62 \%$ - género masculino & \multirow{2}{*}{$\begin{array}{l}100 \text { \% de estudiantes } \\
\text { que responden más } \\
\text { o menos. }\end{array}$} & 35 \% género masculino \\
\hline & 38 \% - género femenino & & 65 \% género femenino \\
\hline \multirow{2}{*}{$\begin{array}{l}\text { Universo de } 26 \\
\text { escolares. }\end{array}$} & $50 \%$ cursan de $1^{\circ}$ a $4^{\circ}$ básico & \multirow{2}{*}{$\begin{array}{l}\text { Universo de } 17 \\
\text { escolares. }\end{array}$} & $53 \%$ cursan de $1^{\circ}$ a $4^{\circ}$ básico \\
\hline & $50 \%$ cursan de $5^{\circ}$ a $8^{\circ}$ básico & & $47 \%$ cursan de $5^{\circ}$ a $8^{\circ}$ básic \\
\hline
\end{tabular}

Para la pregunta 3, abierta y de respuesta corta (¿qué es lo que más te llama la atención de tus compañeras y compañeros extranjeros?), no contestó o contestó no saber un $34 \%$; para el resto de las respuestas (es decir, el $76 \%$ ) se logró segmentar cuatro unidades semánticas: lengua, características físicas, características personales positivas y características personales negativas. La más importante es la referida a la lengua, con un 35\% de interés, reiteradamente nombrada por escolares de género femenino y cursando el primer ciclo básico. El porcentaje de las características personales negativas es muy bajo; se leen respuestas como «bulliciosos» y «gritones». En las respuestas que indican características positivas, se leen expresiones como «alegres», «buenos para la pelota»; de las características físicas más recurrentes se hallan «el pelo», «negros», «altos»y «aprenden rápido». 


\section{Discusión}

Frente a la pregunta de investigación (¿cómo representan las y los escolares chilenos de educación básica de una escuela pública de Santiago a sus compañeras y compañeros haitianos?) observamos que la representación se configura fundamentalmente según sea el nivel escolar y el género del estudiantado chileno, variables básicas del estudio. Por un lado, se ve una inclinación a configurar un sujeto migrante interesante, rico culturalmente, con cualidades personales positivas y poseedor de una lengua fabulosa, digna de ser aprendida. Esta representación la generan en su mayoría estudiantes de género femenino y quienes cursan de $1^{\underline{O}}$ a $4^{\underline{O}}$ básico. Por otro lado, un grupo menor y con leve tendencia al género masculino, rechaza la presencia migrante y no valora su cultura. Por último, es relevante que estudiantes, principalmente de $5^{\circ}$ a $8^{\circ}$ año respondan con indecisión, desinterés o apatía con un «más o menos»

Frente a los estudios realizados en la población escolar chilena que coinciden en los hallazgos discriminatorios relevantes (Galaz et al., 2019; Pavez-Soto et al., 2019; Salas et al., 2017; Unicef, 2011), nuestra investigación no concuerda en que sea el racismo la principal representación en la escuela observada. Ciertamente hay discriminación y rechazo, pero porcentualmente no es mayor que la validación y aceptación que muestran nuestros datos. Concordamos, sí, con la Unicef (2011) en que los estudiantes de género masculino configuran más representaciones negativas del migrante, mientras que las niñas tienden a configurar más representaciones positivas.

En este contexto, creemos que desde el mundo que configuran niños, niñas y adolescentes sí existe la posibilidad de integración, aceptación y recreación cultural. Las políticas educativas, por lo tanto, deben integrar los decires propios de la infancia en orden a lograr la configuración de un entramado social que involucre a niños y niñas de forma activa, alejándose del adultocentrismo que, claramente, no ha sido exitoso en la protección de los derechos de la infancia migrante.

En conclusión, el estudiantado chileno en una escuela pública de Santiago representa socialmente al migrante según sus precarias condiciones de acercamiento no modelado sistemáticamente por la escuela ni por el resto de la sociedad chilena. Si se es niño, la representación tiende a producirse de cierta forma, si se es niña, de otra. Si se está en primer ciclo básico, la representación será de una manera, si se cursa segundo ciclo, de otra. Ante esta falta de orientación para los sujetos de representación, aparece el diálogo 
intercultural como un camino vital que derriba representaciones a partir de prejuicios y logra una configuración del otro con base en el conocimiento real del día a día en la escuela. El diálogo intercultural representa el medio y el fin para la construcción de competencias interculturales, definidas por la Unesco como el «conjunto de capacidades necesarias para relacionarse adecuadamente con los que son diferentes de nosotros» (Unesco, 2009, p. 9). De este modo, es posible facilitar el conocimiento recíproco acerca de las perspectivas, objetivos y saberes de los grupos involucrados, aproximándonos a una forma verdaderamente inclusiva de relacionarnos en nuestra sociedad.

Se hace imprescindible el uso de estrategias que orienten los procesos de inclusión hacia espacios de comunicación que no se generarían naturalmente, de manera que todos los interlocutores tengan la posibilidad de escuchar y ser escuchados. De esta manera, se facilita la demolición de aquellas representaciones marcadas por los prejuicios que prevalecen en los imaginarios colectivos, y así podemos avanzar, de manera democrática y reivindicativa, hacia la verdadera integración del alumnado migrante.

Cabe preguntarse, en este punto, si la escuela sola puede contribuir a la aceptación plena del alumnado migrante. Estudios que atienden la migración del estudiantado haitiano a Chile (Campos, 2018, Stefoni et al., 2016) sostienen que es imposible que la escuela pública unitariamente logre mejorar los índices de integración, por lo cual los datos obtenidos son un aporte al estudio y aliento de la convivencia intercultural.

\section{Referencias}

Abric, J. (1994). Prácticas sociales y representaciones. Ediciones Coyoacán.

Amán, R. (2012). En la lengua del otro: la unión europea y el diálogo intercultural como instrumento de exclusión. Universitas, Revista de Ciencias Sociales y Humanas, (17), 51-68. https://doi.org/10.17163/uni.n17.2012.02

Bastidas, F., \& Torrealba, M. (2014). Definición y desarrollo del concepto proceso de invisibilización para el análisis social: una aplicación preliminar a algunos casos de la sociedad venezolana. Espacio Abierto, 23(3), 515-533.

Campos, J. (2018). Diálogo intercultural en las aulas: el caso chileno haitiano. Rexe, Revista de Estudios y Experiencias en Educación, 17(35), 155-166. https://doi.org/f7cp

Campos, J. (2019). Estudiantado haitiano en Chile: aproximaciones a los procesos de integración lingüística en el aula. Revista Educación, 43(1), 1-17. https://doi.org/f7cr 
Casas, J., Repullo, J., \& Donado, J. (2003). La encuesta como técnica de investigación. Elaboración de cuestionarios y tratamiento estadístico de los datos (I). Atención Primaria, 31(8), 527-538. https://doi.org/10.1016/So212-6567(03)70728-8

Castillo, D., Santa-Cruz, E., \& Vega, A. (2018). Estudiantes migrantes en escuelas públicas chilenas. Calidad en la Educación, (49), 18-49. https://doi.org/g6wz

Castro, B., \& Rivas, G. (2006). Estudio sobre el fenómeno de la deserción y retención escolar en localidades de alto riesgo. Sociedad Hoy, 11, 35-72.

Cerón, L., Pérez, M., \& Poblete, R. (2017). Percepciones docentes en torno a la presencia de niños y niñas migrantes en escuelas de Santiago: retos y desafíos para la inclusión. Revista Latinoamericana de Educación Inclusiva, 11(2), 233-246. https://doi.org/f7cs

Cuevas, Y. (2016). Recomendaciones para el estudio de representaciones sociales en investigación educativa. Cultura y Representaciones Sociales, 11(21), 109-140.

Departamento de Extranjería y Migración. (2019). Migración haitiana en Chile. https:// www.extranjeria.gob.cl/media/2016/og/boletin-1.pdf

De Piero, J. L., \& Narvaja, M. E. (2018). Representaciones de género en comentarios digitales en dos Fan Page de Facebook. Revista Latinoamericana de Ciencias Sociales, Niñez y Juventud, 16(2), 759-775.

Espinoza-Díaz, O., González, L., Cruz-Grau, E., Castillo-Guajardo, D., \& Loyola-Campos, J. (2014). Deserción escolar en Chile: un estudio de caso en relación con factores intraescolares. Educación y Educadores, 17(1), 32-50. https://doi.org/10.5294/edu.2014.17.1.2

Galaz, C., Pávez, I., Álvarez, C., \& Hedrera, L. (2019). Polivictimización y agencia de niños y niñas migrantes en Chile desde una mirada interseccional. Athenea Digital, 19(2), e2447.

Galaz, C., Pávez, I., \& Magalhães, L. (2021). Polivictimización de niños/as migrantes en Iquique (Chile). Sí Somos Americanos, 21(1), 129-151. https://doi.org/g6w3

Galaz, C., Poblete, R., \& Frías, C. (2017). Políticas públicas e inmigración: ¿posibilidades de inclusión en Chile? Universitaria.

González, A. (2017). La construcción de la «peligrosidad» del migrante: un análisis sobre las representaciones sociales de miembros del sistema judicial en la Ciudad Autónoma de Buenos Aires. Revista Estudios Socio-Jurídicos, 19(2), 63-95. https://doi.org/g6w4

Higuera, É., \& Castillo, N. (2015). La interculturalidad como desafío para la educación ecuatoriana. Sophia: Colección de Filosofía de la Educación, (18), 147-162. https:// doi.org/10.17163/soph.n18.2015.08

Jodelet, D. (1986). La representación social: fenómenos, conceptos y teoría. En S. Moscovici (Ed.), Psicología social II (469-506). Paidós. 
Marín-Alaniz, J. (2018). Educando en la frontera norte de Chile: el patrimonio cultural desafiando la exclusión social. Estudios Fronterizos, 19, e019. https://doi.org/f7cz

Medina, R., \& Carreño, J. (2015). Editorial: el diálogo intercultural. Lúdica Pedagógica, 2(22), 5-7. https://doi.org/10.17227/01214128.3804

Mendoza, I., \& Lazzaro-Salazar, M. (2019). La representación social del inmigrante en los programas de gobierno de Michelle Bachelet. Papeles de Trabajo, 36, 65-80. https://doi.org/10.35305/.voi36.14

Mora, M. (2002). La teoría de las representaciones sociales de Serge Moscovici. Athenea Digital. Revista de Pensamiento e Investigación Social, 1(2), 1-25. https://doi.org/cwcr

Mora, M. (2018). Política educativa para migrantes en Chile: un silencio elocuente. Polis, $17(49), 231-257$. https://doi.org/10.4067/So718-65682018000100231

Moreno, K., Soto, R., González, M., \& Valenzuela, E. (2017). Rompiendo con los estereotipos: una experiencia educativa con enfoque de género en una escuela básica. Rexe, Revista de Estudios y Experiencias en Educación, 16(32). https://doi.org/g6xb

Moscovici, S. (1979). El psicoanálisis, su imagen y su público. Huemul.

Muñoz, B. (2000). Enseñanza-aprendizaje de lenguas e inmigración: didáctica y solidaridad. Actas del X Congreso Internacional de Asele, Nuevas perspectivas en la enseñanza del español como lengua extranjera (473-480). Asele.

Páez, D. (1987). Características, funciones y procesos de formación de las representaciones sociales. En D. Páez (Ed.), Pensamiento, individuo y sociedad: cognición y representación social (297-317). Fundamentos.

Palacios, Y. (2014). ¿Inmigrantes, la representación del «mal»? A propósito de Haití y República Dominicana. Revista Prolegómenos, 17(34), 162-182. https://doi.org/g6xc

Pavez-Soto, I., Ortiz-López, J., Jara, P., Olguín, C., \& Domaica, A. (2018). Infancia haitiana migrante en Chile: barreras y oportunidades en el proceso de escolarización. Entre Diversidades, (11), 71-97. https://doi.org/10.31644/ED.11.2018.a03

Pavez-Soto, I., Ortiz-López, J., Sepúlveda, N., Jara, P., \& Olguín, C. (2019). Racialización de la niñez migrante haitiana en escuelas de chile. Interciencia, 44(7), 414-420.

Ravetllat, I. (2017). El defensor de los derechos de la niñez en chile: hacia un verdadero garante de su interés superior. Estudios Constitucionales, 15(1), 255-306. https:// doi.org/10.4067/So718-52002017000100009

Rojas, N., Amode, N., \& Vásquez, J. (2015). Racismo y matrices de inclusión de la migración haitiana en Chile: elementos conceptuales y contextuales para la discusión. Polis, 14(42), 217-245. https://doi.org/10.4067/So718-65682015000300011 
Salas, H. (2011). Investigación cuantitativa (monismo metodológico) y cualitativa (dualismo metodológico): el estatus epistémico de los resultados de la investigación en las disciplinas sociales. Cinta de Moebio, (40), 1-21. https://doi.org/c73ksj

Salas, N., Castillo, D., Kong, F., Thayer, L., \& Huepe, D. (2017). Inmigración en la escuela: caracterización del prejuicio hacia escolares migrantes en Chile. Universitas Psychologica, 16(5), 1-15. https://doi.org/10.11144/Javeriana.upsy16-5.iecp

Sanhueza, S., Friz, M., \& Quintriqueo, S. (2014). Estudio exploratorio sobre las actitudes y comportamiento del profesorado de Chile en contextos de escolarización de alumnado inmigrante. Revista Electrónica de Investigación Educativa, 16(3), 148-162.

Silva, L., Aristizábal, A., Gómez, M., González, Y., Acevedo, C., Ortiz, Y., Rodríguez, N., \& Campo, N. (2018). Reconstrucción de experiencias y percepciones propias de jóvenes habitantes de calle. Revista Latinoamericana de Ciencias Sociales, Niñez y Juventud, 16(2), 809-823.

Stefoni, C., Stang, M., \& Riedemann, A. (2016). Educación e interculturalidad en Chile: un marco para el análisis. Estudios Internacionales, 48(185), 153-182.

Superintendencia de Educación. (2016). Niños y niñas migrantes: trayectorias de inclusión educativa en escuelas de la Región Metropolitana. Gobierno de Chile.

Thayer, L. (2014). Plan de acogida y reconocimiento de migrantes y refugiados de la comuna de Quilicura. OIM.

Tijoux, M. (2013). Immigration schools in the city of Santiago: elements for an education opposing racism. Polis, 12(35), 287-307. https://doi.org/f7c8

Tijoux, M., \& Díaz., G. (2014). Inmigrantes, los nuevos bárbaros en la gramática biopolítica de los estados contemporáneos. Quadranti-Rivista Internazionale di Filosofía Contemporánea, 2(1), 1-19.

Unesco. (2009). Informe mundial de la Unesco. Invertir en la diversidad cultural y el diálogo intercultural. Autor.

Unicef. (2011). Informe anual de UNICEF 2011. https://www.unicef.org/colombia/media/ 226/file/Unicef-Annual-Report-2011.pdf

Unicef. (2020). Niños, niñas y adolescentes en Chile 2o2o.https://uni.cf/3 ${ }_{3} \mathrm{FW}_{7} \mathrm{KG}$

Vergara, A., Peña, M., Chávez, P., \& Vergara, E. (2015). Los niños como sujetos sociales: el aporte de los nuevos estudios sociales de la infancia y el análisis crítico del discurso. Psicoperspectivas, 14(1), 55-65. https://doi.org/gjsj86 